\title{
Resenha
}

\section{Resenha: livro Novos caminhos para a construção da paz}

Áureo de Toledo Gomes ${ }^{1}$

Julia Facchini ${ }^{2}$

DOI: 10.5752/P.1809-6182.2020v17n2p61

Recebido em: 07 de dezembro de 2019 Aceito em: 04 de maio de 2020

Reclaiming Everyday Peace é a tentativa mais sistematizada de apresentar conceitual e empiricamente o projeto dos Everyday Peace Indicators, que busca construir indicadores de paz e conflito a partir da população local. Dividido em duas partes, o livro de Pamina Firchow ora resenhado desenvolve seu argumento discutindo os fundamentos teóricos e epistemológicos dos Everyday Peace Indicators (parte 1) para, em seguida, apresentar a utilização dos mesmos nas comunidades de Odek e Atiak, Uganda, e El Salado e Don Gabriel, Colômbia (parte 2).

Conceitualmente, o livro não apresenta novidades ao debate, já que Firchow está alinhada com as ideias da literatura sobre a Virada Local. Nesse sentido, a dimensão local deve ser inserida, segundo a autora, devido a três motivos principais. Primeiramente, incluir as comunidades para que elas próprias definam paz ajuda na determinaçáo dos objetivos dos projetos de peacebuilding. Em segundo lugar, a população local é detentora de conhecimentos que pessoas de fora da comunidade não tem, sobretudo sobre tradiçóes, práticas e dinâmicas que podem ajudar na construçáo da paz. Por fim, a construção de definiçôes e indicadores deve ser priorizada para a efetividade dos esforços da construção da paz.

A principal inovação teórica do trabalho é a distinção entre Big-P peacebuilding e small-p peacebuilding. Segundo ela, Big-P peacebuilding faz referência aos esforços da comunidade internacional para transformar países saídos de conflitos informados teórica e politicamente pela paz liberal. O foco desses esforços recai sobre elementos técnicos e estruturais, como segurança, governança, Estado de Direito e promoção democrática. Por outra perspectiva, small-p peacebuilding centra-se na capacidade de agência e transformação/construção de relacionamentos. O pressuposto é que a construção e transformação de relacionamentos é constitutiva para a realização de esforços estruturais como acordos de paz, por exemplo.

\footnotetext{
1 Professor Adjunto IV do Instituto de Economia e Relaçôes Internacionais da Universidade Federal de Uberlândia, atuando na graduação e na pós-graduação em Relaçôes Internacionais. Doutor em Ciência Política pela Universidade de São Paulo (2012) e estágio pós-doutoral pela The University of Manchester, Humanitarian and Conflict Response Institute (2014-2015). É atualmente Visiting Scholar na George Mason University, School for Conflict Analysis and Resolution, financiado pela Comissão Fulbright. ORCID: https://orcid.org/0000-0002-6083-0562. Contato: aureotoledo@ufu.br.

2 Mestre em Relaçóes Internacionais pela Universidade Federal de Uberlândia. ORCID: https://orcid.org/0000-0003-2347-3700. Contato: juliafacchini9@gmail.com.
} 
A construção dos indicadores inicia-se com a formação de um grupo focal. Todavia, ao invés utilizar o grupo focal apenas para construir questionários que posteriormente seriam submetidos para os participantes, Firchow leva este procedimento metodológico além. A autora faz com que tais grupos se tornem o fórum no qual membros das comunidades criem e selecionem os indicadores que servirão de base para os questionários. Em cada uma das quatro comunidades, três grupos focais foram constituídos, com uma composição de oito a doze participantes cada um. Ademais, para a escolha dos participantes, os critérios selecionados vinham da demografia da comunidade, envolvendo etnicidade, status socioeconômico, papeis de liderança e gênero.

Os indicadores construídos para comunidades sob análise foram divididos nas seguintes categorias: economia; infraestrutura; saúde; educação; alimentação e agricultura; liberdade; segurança diária; coesão e interdependência; resolução de conflitos; liderança; discriminação; justiça de transição e direitos humanos; e atividades sociais rotineiras. Tais categorias eram comuns para todas as comunidades, porém os indicadores específicos variavam conforme a comunidade, posto que foram construídos por cada uma delas. Nesse sentido, para Atiak foram construídos 13 indicadores; para Odek, 14; Don Gabriel, 21; e El Salado, 20. Aqui, destacaríamos, por exemplo, os seguintes: people dig in their gardens (comum a Atiak e Odek); people are able to participate in traditional festivals, rituals and cultural practices (Odek); ability to study (Don Gabriel); e income opportunities to women (El Salado).

Cumprida essa etapa de elaboração, os questionários foram aplicados às comunidades. Além das perguntas sobre os indicadores, res- pondentes eram perguntados sobre índices de educação, localização dentro das comunidades, gênero, identidade étnica, entre outros. Ao total, foram conduzidos 2.038 surveys para todo o livro. Em El Salado e Don Gabriel, Colômbia, foram conduzidos 1.230 , enquanto 808 foram realizados em Atiak e Odek, Uganda.

Um primeiro achado relevante da pesquisa é que comunidades com altos níveis de intervenção priorizam indicadores relacionados a questóes sociais, como resolução de conflitos e reconciliação. Um segundo importante achado é que localidades com mais intervenção relatam maiores níveis de desenvolvimento em comparação às comunidades com menos intervenção. Todavia, ainda que apresentem mais desenvolvimento, relatam maiores níveis de insegurança. Logo, temos uma situação em que intervenções centradas em projetos de desenvolvimento são efetivas, porém podem vir com o custo de um nível mais alto de insegurança. Em contrapartida, comunidades com pouca intervenção externa percebem mais segurança do que comunidades com muita intervenção.

Em linha semelhante ao achado anterior, outro resultado relevante é que localidades saturadas com altos níveis de intervenção não apresentam necessariamente altos níveis de paz de acordo com os indicadores selecionados. Isto aponta para a disparidade existente entre o que as comunidades querem e priorizam quando definem paz e o que as intervençôes externas priorizam em seus projetos de peacebuilding.

Quais os impactos dos achados específicos do estudo para o debate acadêmico e político mais amplo sobre peacebuilding? Em primeiro lugar, Firchow argumenta que quando houver um aumento na ajuda externa e no número de pessoas em uma determinada intervenção, seria importante que tais açóes fossem acompa- 
nhadas de programas de small- $p$ peacebuilding, pensados para atender as necessidades de coesão social e relacionamento das comunidades. Em segundo lugar, há de se destacar que paz no nível local é multidimensional, dependente do contexto e dinâmica.

A despeito de determinadas questóes em aberto - por exemplo, não se engajar com os críticos e tampouco repensar as premissas teóricas da Virada Local à luz de seus achados, assim como fazer uma apresentação apenas sumária dos estudos de caso - , o livro de Firchow presta-se como uma importante contribuição para a literatura que destaca a importância da dimensão local para a construção da paz.

\section{Referência}

FIRCHOW, Pamina. Reclaiming Everyday Peace: local voices in measurement and evaluation after war. Cambridge: Cambridge University Press, 2018, 206 p. ISBN: 978-1108402767. 